\title{
Descriptive Study to Assess the Knowledge of Staff Nurses Regarding Forensic Psychiatry at Selected Hospitals, Amritsar
}

Amandeep K Bajwa ${ }^{1}$, Rupinder Kaur ${ }^{2}$, Sandeep Kaur ${ }^{3}$, Shabnam ${ }^{4}$, Shivam Sharma ${ }^{5}$, Simranjeet Kaur ${ }^{6}$, Simranjit Kaur ${ }^{7}$, Sukhwinder Kaur ${ }^{8}$, Sumanjeet Kaur ${ }^{9}$

\begin{abstract}
Introduction: Forensic psychiatry is a subspecialty of psychiatry that focuses on the interface between psychiatry and the law. Nurse practising in this unique specialty may apply their skills to the care of both victims and perpetrators of crime and in a variety of settings including primary care facilities, hospitals, and correctional institutions.

Material and methods: The descriptive study design was applied to assess the level of knowledge on forensic psychiatry among staff nurses at selected hospitals, Amritsar. Sixty staff nurses were selected using convenient sampling technique. The tool contained demographic and clinical variables and a self-structured knowledge questionnaire regarding forensic psychiatry, which was distributed to collect the data.

Results: The results of the study show the level of knowledge of staff nurses regarding forensic psychiatry, revealing that 39(65\%) had excellent knowledge and $21(35 \%)$ had good knowledge with an average mean and standard deviation (SD) of $21.38 \pm 3.23$. The findings of the study conclude that staff nurses working in psychiatry and critical care units have less knowledge regarding forensic psychiatry.

Conclusion: There is a need to arrange in-service education regarding forensic psychiatry and also a need for continued and intensified efforts to ensure that staff nurses who are involved in providing quality healthcare services must acquire knowledge and skills necessary about legal and ethical issues and the effects of misuse of law and negligence of nursing practice.

Keywords: Forensic psychiatry, Knowledge, Staff nurses.

AMEI's Current Trends in Diagnosis \& Treatment (2019): 10.5005/jp-journals-10055-0075
\end{abstract}

\section{INTRODUCTION}

Forensic psychiatry is a subspecialty of psychiatry that focuses on the interface between psychiatry and the law. ${ }^{1}$ It may involve evaluating individual involved in the legal system, working in corrections, having involvement in legal issues related to practice, and teaching and performing research in forensic psychiatry. ${ }^{2}$ Forensic evaluation differs from clinical evaluation in that there is no doctor-patient relationship with an implicit duty of care, and confidentiality is limited in as much as reports that are being prepared for use in court. ${ }^{3}$ The American Academy of Child and Adolescent Psychiatry has issued practice parameters for the forensic evaluation of children and adolescent who may have been physically or sexually abuse, child custody evaluation, assessment and treatment of youth in juvenile detention, and correctional facilities. ${ }^{4}$ As more youth enter the juvenile justice system, there is a growing need for forensic psychiatrists who are willing to perform evaluations for the court or work within juvenile corrections providing evaluation and treatment for detainees and committed youths. ${ }^{5}$ There is a high prevalence of psychiatric disorders in this population, and many youth remain undiagnosed. ${ }^{6}$

Forensic nursing is an example of nursing role that is rapidly increasing in its scope of practice. Nurse practising in this unique specialty may apply their skills to the care of both victims and perpetrators of crime and in a variety of settings including primary care facilities, hospitals, and correctional institutions. ${ }^{7}$ The international association of forensic nurses and the American nurses association defined forensic nursing as "The practice of nursing globally when health and legal systems intersect." Forensic nursing is an emerging field that forms an alliance between nursing law enforcement and the forensic sciences. ${ }^{8}$ The term "forensic" means anything belonging to or pertaining to the law forensic nurses
${ }^{1-9}$ Department of Nursing, Sri Guru Ram Das College of Nursing, Sri Guru Ram Das University of Health Sciences, Amritsar, Punjab, India

Corresponding Author: Amandeep K Bajwa, Department of Nursing, Sri Guru Ram Das College of Nursing, Sri Guru Ram Das University of Health Sciences, Amritsar, Punjab, India, Phone: +91 9814135471, e-mail: amanbajwaroop@gmail.com

How to cite this article: Bajwa AK, Kaur R, Kaur S, et al. Descriptive Study to Assess the Knowledge of Staff Nurses Regarding Forensic Psychiatry at Selected Hospitals, Amritsar. AMEl's Curr Trends Diagn Treat 2019;3(2):56-58.

Source of support: Nil

Conflict of interest: None

provide a continuum of care to victims and their families beginning in the emergency room or crime scene and reading to participation in the criminal investigation and the courts of law. ${ }^{9}$ Clinical forensic nursing is the management of crime victims from trauma to trial. Nurses working in clinical forensics collect evidence through assessment of living victims, survivors of traumatic injury, or those whose death is pronounced in the clinical environment. Clinical forensic nursing involves making judgments related to patient treatment associated with court-related issues. ${ }^{10}$ Many nurses come to forensic nursing from acute care settings of emergency department nursing, critical care nursing, and preoperative nursing. ${ }^{11}$ Forensic patients are treated in a variety of settings including country jails, correctional facilities, psychiatric hospitals, and the community. Nursing care is very challenging because the rules of the criminal justice system are often at odds with nursing practice standards. ${ }^{12}$ Forensic psychiatry deals with the legal aspects of psychiatry. Psychiatry nurse should be sufficiently aware of the 
legal aspects of psychiatry. This will help protect the patient's right and avoid in giving poor advice or innocently involving herself in legal issues. Legal aspects help at many points in psychiatric care side through admission of a mentally ill person in a mental hospital, civil responsibility, criminal responsibility, and standards of care. ${ }^{13}$

\section{Materials and Methods}

A quantitative research approach with descriptive design was used to assess the knowledge of staff nurses regarding forensic psychiatry. The study was conducted at Tertiary Care Teaching Hospital and Vidya Sagar Mental Hospital, Amritsar, in June 2018. A convenient sampling technique was used to select the 60 staff nurses. The tool consists of two sections, i.e., the sociodemographic variables and clinical variables and self-structured knowledge questionnaire regarding forensic psychiatry. The sociodemographic variables include age, gender, professional qualification, type of habitat, and family income per month, and clinical variables of staff nurses include clinical experience in years, working area, source of knowledge, and any formal training on forensic psychiatry. A selfstructured knowledge questionnaire regarding forensic psychiatry consists of 26 items regarding forensic psychiatry. The questionnaire was prepared and finalized from extensive review of literature and validated by experts. After maintaining rapport and explaining the purpose of study to staff nurses, a self-structured knowledge questionnaire was distributed (Fig. 1).

\section{Statistical Analysis}

Data were collected, organized, and analyzed by Statistical Package for the Social Sciences Version 16. Computation of frequencies and percentage was done for the analysis of sociodemographic and clinical variables. For assessing the level of knowledge regarding forensic psychiatry among staff nurses, arithmetic mean and SD were calculated. To find out the association between knowledge score and sociodemographic variables which was tested by nonparametric Chi-square test at $p$ value $<0.05$.

\section{Ethical Consideration}

The study has been approved by ethical committee of Sri Guru Ram Das Institute of Medical Sciences and Research, Amritsar. A written informed consent was taken from each study subject after informing him or her about the nature of study. The confidentiality was maintained throughout the study.

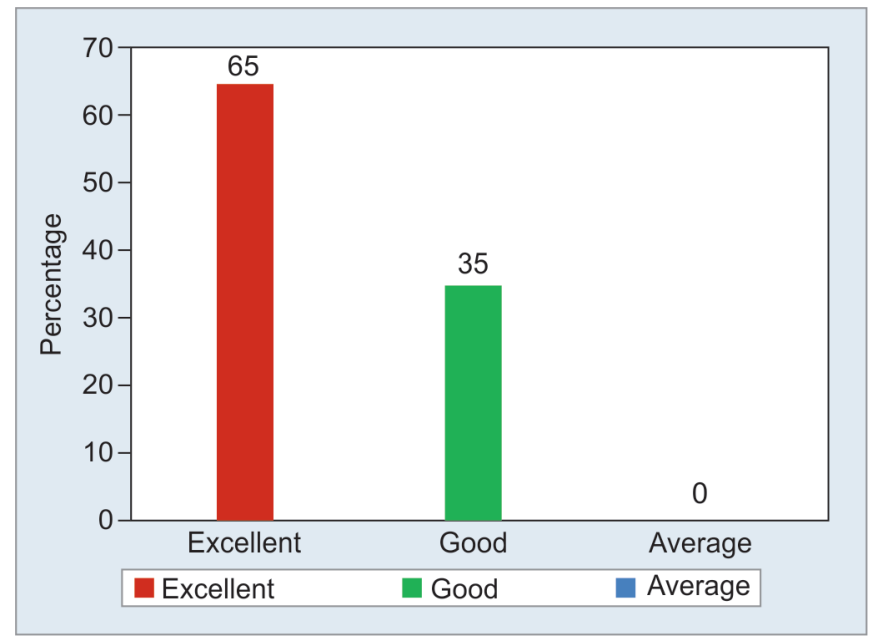

Fig. 1: Level of knowledge

\section{Results}

Table 1 shows the frequency and percentage distribution of sociodemographic variables, revealing that $44(73.3 \%)$ were in the age group of 20-30 years, 12 (20\%) were in the age group of 31-40 years, $3(5 \%)$ were in the age group of $41-50$ years, and $1(1.7 \%)$ was in the age group of $51-60$ years. In total, $58(96.7 \%)$ of staff nurses were female and 2 (3.3\%) were male. Professional qualification of staff nurses: 35 (58.3\%) had completed General Nursing and Midwifery (GNM), 21 (35\%) had completed BSc Nursing, 3 (5\%) had completed Post BSc Nursing, and 1 (1.7\%) had completed MSC Nursing. Type of habitat: 22 (36.7\%) of staff nurses were residing in the rural area, 33 (55\%) were residing in the urban area, and 5 (8.3\%) were residing in the semi-urban area. Family income of staff nurses: 39 (65\%) were earning less than Rs. 10,000 per month, 15 (25\%) were earning Rs. 10,001-20,000 per month, and 6 (10\%) were earning above Rs. 20,000 per month.

Table 2 shows the results of clinical variables of staff nurses, revealing that $30(50 \%)$ have $1-5$ years of clinical experience, 12 (20\%) have 6-10 years of clinical experience, 11 (18.3\%) have less than 1 year of clinical experience, $4(6.7 \%)$ have $11-15$ years of clinical experience, and 3 (5\%) have above 15 years of clinical experience. In total, 50 (83.3\%) of staff nurses in the other ward and $10(16.7 \%)$ were working in the psychiatric ward. In total, $52(86.7 \%)$ had source of knowledge through in-service education and 8 (13.3\%) had source of knowledge from conference/workshop regarding forensic psychiatry. In total, 17 (28.3\%) had no formal training and 43 (71.7\%) had formal training on forensic psychiatric nursing.

Table 3 shows the results of level of knowledge of staff nurses regarding forensic psychiatry, revealing that 39 (65\%) had excellent knowledge and 21 (35\%) had good knowledge with an average mean and SD of $21.38 \pm 3.23 .{ }^{14,15}$

Table 1: Frequency and percentage distribution of sociodemographic variables

\begin{tabular}{|c|c|c|c|}
\hline S. no & Demographic variables & Frequency & Percentage \\
\hline \multirow[t]{5}{*}{1} & Age (years) & & \\
\hline & $20-30$ & 44 & 73.3 \\
\hline & $31-40$ & 12 & 20 \\
\hline & $41-50$ & 3 & 5 \\
\hline & $51-60$ & 1 & 1.7 \\
\hline \multirow[t]{3}{*}{2} & Gender & & \\
\hline & Male & 2 & 3.3 \\
\hline & Female & 58 & 96.7 \\
\hline \multirow[t]{5}{*}{3} & Professional qualificatio & & \\
\hline & GNM & 35 & 58.3 \\
\hline & BSc Nursing & 21 & 35 \\
\hline & Post BSc Nursing & 3 & 5 \\
\hline & MSc Nursing & 1 & 1.7 \\
\hline \multirow[t]{4}{*}{4} & Type of habitat & & \\
\hline & Rural & 22 & 36.7 \\
\hline & Urban & 33 & 55 \\
\hline & Semi-urban & 5 & 8.3 \\
\hline \multirow[t]{4}{*}{5} & Family income per mont & Rs) & \\
\hline & $<10,000$ & 39 & 65 \\
\hline & $10,001-20,000$ & 15 & 25 \\
\hline & $>20,000$ & 6 & 10 \\
\hline
\end{tabular}




\begin{tabular}{|c|c|c|c|}
\hline S. no & Demographic variables & Frequency & Percentage \\
\hline \multirow[t]{6}{*}{1} & \multicolumn{3}{|l|}{ Clinical experience in years } \\
\hline & $<1$ & 11 & 18.3 \\
\hline & $1-5$ & 30 & 50 \\
\hline & $6-10$ & 12 & 20 \\
\hline & $11-15$ & 4 & 6.7 \\
\hline & $>15$ & 3 & 5 \\
\hline \multirow[t]{3}{*}{2} & \multicolumn{3}{|l|}{ Working area } \\
\hline & Psychiatric ward & 10 & 16.7 \\
\hline & Other ward & 50 & 83.3 \\
\hline \multirow[t]{3}{*}{3} & \multicolumn{3}{|l|}{ Source of knowledge } \\
\hline & Conference/workshop & 8 & 13.3 \\
\hline & In-service education & 52 & 86.7 \\
\hline \multirow[t]{3}{*}{4} & \multicolumn{3}{|c|}{ Have you ever had any formal training } \\
\hline & Yes & 17 & 28.3 \\
\hline & No & 43 & 71.7 \\
\hline
\end{tabular}

Table 3: Level of knowledge of staff nurses regarding forensic psychiatry

\begin{tabular}{llllll}
\hline S.no & Level of knowledge & $F$ & Percentage & Mean & SD \\
\hline 1 & Excellent $(>75 \%)$ & 39 & 65 & 21.38 & 3.23 \\
2 & Good $(50-75 \%)$ & 21 & 35 & & \\
3 & Average $(<50 \%)$ & 0 & 0 & & \\
\hline
\end{tabular}

\section{Discussion}

The study shows the results of level of knowledge of staff nurses regarding forensic psychiatry, revealing that 39 (65\%) had excellent knowledge and 21 (35\%) had good knowledge with an average mean and SD of $21.38 \pm 3.23$. A similar descriptive comparative study was conducted by Barnabas et al. ${ }^{16}$ in India (Ludhiana). The major findings were the BSc nursing graduates exhibited better legal responsibility knowledge score (mean\% of 71.43) than diploma graduates (mean\% of 68.5). According to Hariharans, Jonnalagadda, Walrond, Moseley, ${ }^{17}$ in West Indies, only $52 \%$ of the doctors and $37 \%$ of the nurses knew little of the law pertaining to their work. A quarter of nurses knew nothing about nurse's code of ethics. The result reveals that the demographic variables such as age, gender, professional qualification, habitat, and family income were not found any significant association with knowledge score of staff nurses regarding forensic psychiatry.

Dr Murthy conducted a descriptive study to assess the knowledge among 30 staff nurses regarding legal and ethical responsibilities in the field of nursing at selected psychiatric center of Jaipur, Rajasthan. The findings of the study revealed that majority $(90 \%)$ of the nurses possessed moderate level of knowledge, 105 of nurses possessed high level of knowledge, and none of nurses possessed low level of knowledge. The mean score obtained in the legal areas was $25.1 \pm 3.1$, whereas that obtained in the ethical area was $13.9 \pm 2.7$. This indicates knowledge deficit in both legal and ethical areas, and there was not a significant association found between the knowledge with the demographic variables. $^{12}$

\section{IMPLICATIONS FOR NURSING}

The student nurses must be aware of legal aspects of forensic psychiatric nursing to protect themselves from legal problems.

\section{Conclusion}

The findings of the study conclude that staff nurses working in the psychiatry ward have less knowledge regarding forensic psychiatry. It is necessary to make specialization in the area of forensic nursing. So, there is a need for continued and intensified efforts to ensure that staff nurses who are involved in providing quality healthcare services in the psychiatry ward must acquire knowledge and skills necessary about legal and ethical issues and the effects of misuse of law and negligence of nursing practice. Forensic emergency nursing skills need to be provided to nurses working in casualty, critical care units, and psychiatry department.

\section{References}

1. Mary. BA. Psychiatric Nursing: Contemporary Practice. 4th ed., New Delhi: Wolters Kluwer; 2008. p. 771.

2. Sadock's, Kaplan. Comprehensive Text Book of Psychiatry. 9th ed., vol. 2, New York: Walters Kluwer, Lippincott Williams and Wilkins; 2009. p. 3834.

3. Townsend Mary C. Psychiatric mental health nursing: Concepts of care in evidence- based practice. 7th ed., Philadelphia: F.A. Davis Company; 2012. pp. 917-919.

4. Raj Bhaskara Elakkuvana D. Mental health (Psychiatric Nursing). Banglore: Emmess; 2014. p. 16.

5. Salize HJ, Schanda H, Dressing H. From the hospital into the community and back again-a trend towards reinstitutionalization in mental health care? Int Rev Psychiatry 2008;20(6):527-534. DOI: $10.1080 / 09540260802565372$.

6. Vyas JN. Textbook of post graduate psychiatry. New Delhi: Jaypee Brothers; 2003. p. 998.

7. William J, Richardson $S$, O'Donovan $P$, et al. The forensic nurse practitioner role (emergency nursing) potential response to changing health needs in New Zealand; emergency department, christ church hospitals New Zealand. Med Law 2005;24(1):111-123.

8. Kumar H, Gokhale, Jain K. Legal awareness and responsibilities of staff nurse in administration of patient care. J Clin Diagn Res 2013;7(12):2814-2817. DOI: 10.7860/JCDR/2013/7737.3886.

9. Ghimire Vyas. Text book of post graduate psychiatry. 3rd ed., vol. 2, New Delhi: Jaypee Brothers; 2016. p. 2070.

10. Sukhpal K. Nursing research and statistics. New Delhi: CBS publishers; 2016. p. 40

11. Polit D. A study to assess the attitude towards rights of hospitalized psychiatric patients. 6th ed., New Delhi: Walters; 2008. Avaliable on www.rguhs.ac.in>onlinecdc>upload.

12. Murthy. P, Mental Health Care in India. Concerns for Law reform, Forensic psychiatric nursing; 2011 August 2:3:10-12.

13. Suresh KS. A study to assess the awareness regarding human rights of mentally ill among staff nurses. 2009. Available on www.rguhs. ac.in $>$ onlinecdc $>$ upload.

14. Kunjumon Betty P. The knowledge and practice of trained nurses in protecting patient rights and factors interfering them. Nurs J India 2006;XC 2(4):90-91.

15. Ozdemir Haken M. Midwives and nurses awareness of patient's rights. Midwifery 2009;25(6):756-765. DOI: 10.1016/j.midw.2008.01.010.

16. Barnabas $S$. Study to assess knowledge of legal responsibilities in patient care among graduates. Nurse J India 2004;95(4):90-91.

17. Hariharan $S$, Jonnalagadda $R$, Walrond E, et al. Knowledge, attitudes and practice of healthcare ethics and law among doctors and nurses in Barbados. BMC Med Ethics 2006;7(1):E7. DOI: 10.1186/1472-6939-7-7. 